\title{
Nupcialidade indígena: possibilidades e limitações de análise utilizando os dados do Censo Demográfico de $2010^{\star}$
}

\author{
Luciene Aparecida Ferreira de Barros Longo ${ }^{\text {* }}$ \\ Luciane Ouriques Ferreira ${ }^{\star \star *}$ \\ Marta Maria do Amaral Azevedo ${ }^{\star \star \star \star}$
}

O presente artigo analisa os dados disponíveis na amostra do Censo Demográfico de 2010 a respeito da nupcialidade da população autodeclarada indígena. Se há uma significativa produção antropológica sobre organização social dos povos indígenas no Brasil, o que contempla aspectos referentes a casamentos, pouco se sabe, a partir de uma perspectiva demográfica, sobre a nupcialidade desse segmento da população e como se dão as uniões endogâmicas e exogâmicas considerando os grupos de raça/cor. Assim, tem-se como objetivo apresentar uma análise dos padrões de nupcialidade, utilizando as categorias pesquisadas do quesito raça/cor no Censo Demográfico de 2010, com foco na população indígena. Especificamente se realiza uma análise da idade média à união e ao casamento e das taxas de homogamia por raça/ cor, inclusive separando os casais por grupos de idade da mulher, status marital, situação do domicílio e residentes em municípios com Terras Indígenas. Apesar das evidentes limitações dos dados, e com uso de métodos demográficos indiretos, os resultados revelam que, entre todas as categorias de raça/cor, a idade média à união dos indígenas é a menor e suas taxas padronizadas de endogamia por raça/cor são as mais altas.

Palavras-chave: Nupcialidade. Indígenas. Raça/cor. Censo Demográfico. Brasil.

\footnotetext{
* Este trabalho é de inteira responsabilidade das autoras, não tendo a instituição à qual pertencem nenhuma responsabilidade sobre esta publicação.

** Instituto Brasileiro de Geografia e Estatística (IBGE), Rio de Janeiro-RJ, Brasil (lulongo@gmail.com).

${ }^{* \star *}$ Fundação Oswaldo Cruz (Fiocruz), Rio de Janeiro-RJ, Brasil (lu.ouriquesf@gmail.com).

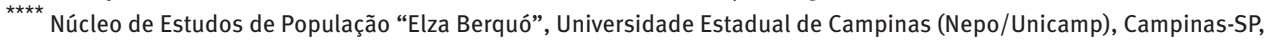
Brasil (marta@nepo.unicamp.br).
} 


\section{Introdução}

A investigação sobre os padrões de nupcialidade é parte central das análises demográficas de uma dada população. Como amplamente reconhecido, o estado conjugal, os tipos de união e as idades de início das uniões exercem influências sobre os complexos processos de formação e manutenção da família e podem impactar diretamente sobre as dinâmicas de fecundidade (HEY, 2008; LAPLANTE et al., 2015; SIEGEL; STOCKWELL, 1976).

No caso da população brasileira, na demografia existe uma bem-estabelecida vertente de análises sobre as transformações nos padrões de nupcialidade (BERQUÓ; OLIVEIRA, 1992; RIBEIRO; SILVA, 2009; LONGO, 2014; VIEIRA; ALVES, 2014), o que reflete uma tendência de ampliação de interesse sobre o tópico observável em outros países da América Latina (LAPLANTE et al., 2015). Nessa literatura, alguns dos principais temas investigados incluem as relações entre nupcialidade e redução da fecundidade, participação das mulheres no mercado de trabalho, cor ou raça dos conjugues, entre diversos outros (BERQUÓ; OLIVEIRA, 1992; RIBEIRO; SILVA, 2009; LONGO, 2014; VIEIRA; ALVES, 2014; LAPLANTE et al., 2015).

Uma questão importante nas investigações sobre nupcialidade no Brasil diz respeito à chamada "seletividade marital”, investigada por Longo (2011). Essa vertente analítica parte do reconhecimento de que uniões podem ocorrer tanto entre grupos "homogêneos" (indivíduos de características semelhantes que se unem - "endogamia”) quanto entre grupos "heterogêneos" (união entre indivíduos com características distintas - "exogamia”). Na literatura sobre o tema, casamentos exogâmicos são tidos como uma transposição de fronteiras sociais, uma vez que envolvem a aceitação de um parceiro com uma característica marcadamente diferenciada (QIAN, 1997; FU, 2001; GULLICKSON, 2006; LONGO, 2014). No tocante à seletividade marital, a dimensão da cor ou raça tem recebido particular atenção no Brasil (PETRUCELLI, 2001; TELLES, 2003; RIBEIRO; SILVA, 2009; LONGO, 2011).

Em geral, amarelos e indígenas não têm sido incluídos nesses estudos que apresentam análises sobre homogamia por cor/raça na demografia, pois constituem parcelas bastante reduzidas da população do país, dificultando os procedimentos de análise comparativa nas investigações a partir de dados amostrais e, principalmente, quando o foco da análise é a população em geral (LONGO, 2011). No tocante aos povos indígenas, acrescenta-se o fato que a população classificada na categoria “indígena” tem apresentado grandes variações no total deste segmento populacional nas últimas décadas. Adicionalmente, e talvez mais importante ainda, deve-se reconhecer que há grande heterogeneidade interna quanto à forma de organização e escolhas matrimoniais nas diferentes etnias abrigadas na categoria "autodeclarados indígenas" na informação sobre raça/cor, como captada no questionário da amostra dos Censos Demográficos brasileiros.

Os trabalhos antropológicos específicos sobre casamento, por outra parte, enfocam as trocas matrimoniais definidas enquanto sistemas operados por categorias sociais próprias de cada sociedade indígena (AZEVEDO, 2005). As escolhas matrimoniais de um cônjuge 
(não importa se homem ou mulher) são feitas a partir de determinado sistema de parentesco, em que a própria terminologia já define os círculos de parentes consanguíneos e afins, ou seja, aqueles com os quais cada pessoa já sabe que é potencialmente cônjuge. Esses sistemas que operam no interior de cada uma das culturas/povos indígenas levam em conta grupos sociais (clãs, linhagens, metades exogâmicas entre outros) que não foram passíveis de pesquisa pelo Censo Demográfico.

A multiplicidade inerente à categoria “indígena”, captada no Censo Demográfico de 2010, pode ser dimensionada pelos diversos segmentos identificados a partir das informações coletadas: povos indígenas residentes em Terras Indígenas ( $\mathrm{TI}$ ); indígenas residentes em áreas rurais e urbanas fora de Terras Indígenas que declararam pertencimento étnico a etnias específicas; pessoas que se classificaram como indígenas, mas sem indicação de filiação étnica específica; entre outros (IBGE, 2012a). No entanto, apesar de estarem incluídas tanto no questionário básico quanto no da amostra, por motivos de sigilo e representatividade amostral, nem todas essas informações foram divulgadas nos microdados da amostra, onde está presente a informação sobre nupcialidade.

Mesmo que não seja possível estimar a endogamia/exogamia segundo as diferentes categorias sociológicas, é importante voltar a atenção para a diversidade interna da categoria disponível para análise. No entanto, deve-se salientar que os povos indígenas no Brasil fazem parte de totalidades sociológicas distintas pertencentes a um grande conjunto de povos das terras baixas sul-americanas, sendo que a categoria "indígena" só faz sentido se pensada no contexto histórico social do Brasil. Esses povos têm sido estudados do ponto de vista de suas organizações sociais, incluindo, portanto, as chamadas relações de descendência e aliança, terminologia de parentesco e composição de grupos sociais (SHAPIRO, 1984).

Nesse contexto, e cientes das limitações das análises possíveis com os dados disponíveis, o presente artigo tem como objetivo apresentar uma análise demográfica dos padrões de nupcialidade, utilizando as categorias pesquisadas do quesito raça/cor no Censo Demográfico de 2010, com foco na população indígena. Especificamente se realizará uma análise da idade média à união e ao casamento e das taxas de homogamia por raça/ cor para diferentes recortes populacionais.

Vale ressaltar que este artigo parte do pressuposto de que as análises dos dados dos Censos Demográficos referentes à nupcialidade, principalmente no tocante à categoria “indígena”, são limitadas e carregam um viés etnocêntrico demográfico considerável. Daí a importância de se manter um contínuo diálogo com o campo da antropologia, de modo a se levar em conta (ou ao menos se reconhecer) sistemas socioculturais da população indígena que podem influenciar a interpretação dos perfis de nupcialidade. Adicionalmente, como se verá mais adiante, a forma de coleta dos dados no Censo Demográfico de 2010 apresentou problemas de identificação dos parceiros/companheiros nos setores censitários das Terras Indígenas, o que precisa ser mais bem captado em novas edições dos Censos. 


\section{Breve panorama sobre a nupcialidade indígena}

Nas duas últimas décadas, em particular devido à inclusão da categoria indígena na pergunta sobre cor ou raça a partir do Censo 1991, tem havido um crescente interesse em investigações demográficas sobre os indígenas no Brasil de uma perspectiva censitária (AZEVEDO, 2011; IBGE, 2012a; PAGLIARO et al., 2005; SANTOS; TEIXEIRA, 2011). Nessa incipiente literatura, temáticas como estrutura etária e por sexo, fecundidade e distribuição urbano-rural têm recebido mais atenção (IBGE, 2005, 2012a; PAGLIARO et al., 2005), enquanto outras centrais para os estudos populacionais, incluindo nupcialidade, ainda estão por ser mais investigadas.

Uma exceção é a análise sobre nupcialidade indígena com base nos dados dos Censos Demográficos de 1991 e 2000, produzida pelo IBGE em parceria com o Grupo de Trabalho de Demografia dos Povos Indígenas da Associação Brasileira de Estudos de População (Abep) (IBGE, 2005). Esse estudo destacou algumas características relacionadas ao estado conjugal e à idade média ao casar dos indígenas sem, contudo, se aprofundar nessas características. Em relação ao estado conjugal, foram observadas menores proporções de viúvos, separados, desquitados e divorciados em áreas rurais, em comparação com as áreas urbanas. Consequentemente, foram maiores as proporções de solteiros e casados nessas áreas. Embora a idade média ao casar tenha sido menor entre os indígenas, ela aumentou entre 1991 e 2000, tendo-se observado uma diminuição da diferença entre indígenas e o conjunto da população brasileira (IBGE, 2005).

Em relação aos povos indígenas, é importante reconhecer que questões associadas à nupcialidade têm sido, desde longa data, centrais para a área da antropologia, uma vez que se relacionam a temas como sistemas de parentesco, organização social, alianças matrimoniais, relações de gênero e produção de corpos e de pessoas (MAYBURY; LEWIS, 1979; MELATTI, 1987; SEEGER, 1980; TASSINARI, 1995; VIVEIROS DE CASTRO, 1995). As pesquisas antropológicas que abordam aspectos associados à temática da nupcialidade indígena, via de regra, empregam metodologias qualitativas de pesquisa (etnografia) para compreender as dinâmicas socioculturais deste fenômeno junto a sociedades indígenas particulares (MELLATI, 1987; SEEGER, 1980; VIVEIROS DE CASTRO, 1995).

Além das diferenças metodológicas, as pesquisas antropológicas e as demográficas acerca da nupcialidade operam com categorias que, embora por vezes compartilhando uma mesma nomenclatura, possuem acepções distintas e particulares. Por exemplo, grande parte das análises sobre nupcialidade no âmbito da demografia envolve variáveis relacionadas à união (se a mulher ou o homem vive ou não em união e se essa união é formal ou informal), que se apoiam em noções de casamento/matrimônio vigentes na sociedade ocidental (IBGE, 2012b). Já do ponto de vista antropológico, tais categorias são limitadas no sentido de captar as especificidades socioculturais que configuram o fenômeno da nupcialidade entre os povos indígenas no Brasil. Por sua vez, endogamia e exogamia são noções que também assumem acepções conceituais próprias na literatura 
etnológica, remetendo às regras de casamento preconizadas nos diferentes sistemas de organização social, por meio das quais um determinado povo opera para regulamentar as alianças matrimoniais ou no interior do próprio grupo ou entre membros de segmentos sociais externos ao grupo (LEVI-STRAUSS, 1982). No Brasil, há poucos estudos que abordam a questão da nupcialidade indígena articulando ao mesmo tempo perspectivas da demografia e da antropologia (AZEVEDO, 2003, 1994, 2005; COIMBRA JR. et al., 2002; POZZOBON, 1994; TEIXEIRA, 2005). A partir de uma detalhada análise sobre populações indígenas residentes na região do Rio Negro, no Amazonas, Azevedo (2005) evidenciou, por exemplo, que os padrões de fecundidade e espaçamentos entre filhos estão associados ao tipo de casamento, principalmente em relação à exogamia linguística, que, por vez, influencia a idade ao casar e a idade ao ter o primeiro filho.

0 presente artigo constitui uma primeira análise sobre os dados produzidos pelo Censo Demográfico de 2010 a respeito da nupcialidade da população autodeclarada indígena, utilizando os microdados da amostra. Conforme destacado anteriormente, pouco se sabe sobre a nupcialidade desse segmento da população e como ocorrem as uniões entre os indígenas e dos indígenas e demais grupos de raça/cor a partir de uma perspectiva demográfica, o que não deve encerrar a necessidade de análises mais detalhadas por meio de dados não divulgados ao uso público.

Ao mesmo tempo que lança mão de procedimentos analíticos utilizando uma vertente demográfico-quantitativa que possibilita uma aproximação compreensiva do fenômeno da nupcialidade, esta análise pauta-se na perspectiva de manter uma postura reflexiva sobre a forma como os dados captados pelo Censo Demográfico 2010 dialogam com as diferentes dinâmicas socioculturais das populações indígenas, principalmente indicando a potencialidade destas análises e os limites ainda impostos pela coleta dos dados.

\section{Procedimentos metodológicos}

Esta investigação se baseia nos dados da amostra do Censo Demográfico de 2010 (a partir daqui referido como Censo 2010). Embora a questão sobre raça/cor tenha sido pesquisada pela primeira vez pelo questionário do universo no Censo 2010, os dados que permitem realizar a análise das uniões são aqueles da amostra, para a qual foi aplicado 0 questionário mais completo, com um número maior de informações individuais (IBGE, 2013).

Trabalhar com os dados da amostra do Censo Demográfico vem associado a diversas limitações, pois algumas informações importantes para análise da nupcialidade da população indígena, como o pertencimento étnico e a língua falada, só estão disponíveis ao uso público nos dados do universo e publicados de forma agregada. Portanto, o emprego dos dados públicos da amostra acaba sendo um grande limitador na análise da nupcialidade no que tange à endogamia indígena por raça/cor e à exogamia étnica ou linguística. Como a maior parte dos trabalhos demográficos sobre homogamia exclui a população indígena devido ao seu número reduzido em relação às demais categorias de raça/cor, 
como mencionado, pouco se sabe sobre a formação das uniões indígenas comparada a outros segmentos populacionais. Mesmo que a investigação sobre a endogamia no caso dos indígenas tenha que ser feita com cautela, dadas as especificidades desse segmento da população, ainda assim, de nosso ponto de vista, este trabalho traz uma importante contribuição enquanto exemplo de análise sobre a nupcialidade indígena, que poderia ser realizada com os dados publicados e coletados de maneira mais adequada.

\section{Singulate Mean Age at Marriage - SMAM}

Para a análise dos padrões de nupcialidade, foram utilizadas as estimativas de idade média à união e ao casamento, empregando-se o método SMAM (Singulate Mean Age at Marriage) desenvolvido por Hajnal (1953) e descrito de forma pormenorizada por Newell (1988), a partir de informação bastante simples, como a distribuição por idade e sexo. 0 procedimento consiste em calcular a idade média à união e ao casamento, considerando, respectivamente, a proporção de pessoas nunca unidas e a proporção de pessoas com estado civil solteiro. Esse é um método indireto, que supõe que o padrão etário de união/ casamento não mudou nos últimos 20 ou 30 anos e, portanto, consiste em uma medida de uma coorte sintética. 0 método é utilizado quando não se tem a informação da idade das pessoas ao se unir/casar, como é o caso do Censo 2010. Para o Brasil, não há qualquer informação sobre a data da união (atual ou anterior) nos Censos Demográficos, indagando-se apenas ao recenseado a natureza da união (casamento ou união consensual). Assim, utilizando-se o estado conjugal corrente, é possível estimar a idade média à união e ao casamento civil e/ou religioso, que deve ser entendida como o número médio de anos vividos no estado de solteiro entre aqueles que se casam antes dos 50 anos de idade, conforme definido no cálculo desse indicador.

Para fazer uma análise mais ampla, optou-se por calcular a SMAM tanto para a idade média à união quanto para a idade média ao casamento formalizado, ou seja, considerou-se casamento formalizado aquele realizado ou só no civil, ou só no religioso, ou no civil e no religioso. Para esse cálculo, é necessário conhecer o percentual de nunca unidos (pessoas que declararam nunca terem vivido em companhia de cônjuge/companheiro) ou solteiros (de acordo com o estado civil, ou seja, nunca se casaram no civil ou no religioso ${ }^{1}$ ), por grupos etários quinquenais, para pessoas de 15 a 54 anos.

Para esta análise da idade média ao casamento ou união, incluem-se os segmentos populacionais identificados pela autodeclaração de raça/cor, mas subdividindo o grupo de indígenas em residentes em Terras Indígenas, não residentes em Terras Indígenas, residentes em área urbana, residentes em área rural e residentes em municípios com TI, com o intuito de apreender um pouco da diversidade interna a este grupo. Vale ressaltar que nesta análise é considerada toda a população indígena captada pelo Censo e que a

\footnotetext{
${ }^{1}$ Nesse caso, é possível que o indivíduo já tenha estado em uma união consensual, para a qual consideramos também as uniões formalizadas pelos sistemas culturais próprios dos povos indígenas.
} 
informação sobre residentes em Terras Indígenas foi obtida na parte amostral do Censo, a partir da informação sobre municípios que continham pelo menos uma TI. ${ }^{2}$

\section{Taxas de endogamia e exogamia}

Na segunda parte da análise, o foco foi nas mulheres de 20 anos ou mais de idade ${ }^{3}$ e seus maridos ou companheiros, com destaque para as indígenas. A informação sobre maridos e companheiros conviventes no mesmo domicílio é identificada no Censo 2010 por uma pergunta específica para cada mulher que se declarou casada ou unida, em que, no número de ordem na lista de pessoas do domicílio, é identificado seu companheiro ou cônjuge. Esta informação é essencial para o cálculo das taxas de endogamia e exogamia, principalmente em um Censo em que os núcleos familiares reprodutivos não são conhecidos, como foi no caso do Censo $2010 .^{4}$

As taxas de endogamia e exogamia por raça/cor foram calculadas para diferentes grupo de idade da mulher, status marital, situação do domicílio e municípios com Terras Indígenas. Considerou-se endogamia a relação dos casais em que a mulher e seu cônjuge declararam ter a mesma raça/cor. Analogamente, os casais cujos cônjuges eram de raça/ cor distintas foram classificados como exogâmicos.

Antes de se analisarem as taxas de endogamia e exogamia, é preciso padronizar os dados para evitar interpretações equivocadas em função dos tamanhos diferenciados das categorias analisadas. Por exemplo, os grupos de brancos, pardos, pretos e, principalmente, de amarelos e indígenas possuem números bastante distintos de indivíduos. Quando se iguala o tamanho das categorias de raça/cor de homens e mulheres, é possível identificar um "padrão endogâmico intrínseco" da população. Esse procedimento também torna possível eliminar os efeitos de desequilíbrios na razão de sexo por categoria (OLIVEIRA, 2006; PETRUCELLI, 2001).

0 procedimento de padronização baseia-se em um método interativo, cujo objetivo é ajustar as tabelas de contingência por meio das distribuições marginais da raça/cor da mulher e do homem, de modo a manter a mesma associação observada ou estrutura de interação. Tal ajuste é concluído quando se obtêm, para cada linha e coluna, os totais marginais iguais a 100 (AGRESTI, 1990). Para tornar os padrões de associação mais nítidos, foi utilizado o método IPF (Iterative Proportional Fitting), ou método interativo de ajuste proporcional, que consiste na seguinte rotina:

- transformam-se os valores de cada célula na tabela $\left(n_{i j}\right)$ em valores iniciais $\left(\hat{m}_{i j}^{(0)}\right)$ no tempo $t=0$, ou seja, $\hat{m}_{i j}^{(0)}=n_{i j}$;

\footnotetext{
$\overline{2}$ Importante esclarecer que nos dados da amostra não existe a informação sobre Terras Indígenas, portanto, esta variável foi estimada como uma aproximação, a partir da informação sobre os municípios que continham pelo menos uma TI, ou seja, não reflete exatamente a população residente em TI, mas sim toda população, urbana ou rural, que reside em município com TI.

${ }^{3}$ Optou-se por analisar esse grupo de mulheres porque as proporções de mulheres não unidas com idade inferior a 20 anos são muito elevadas e as idades médias à união são maiores e próximas de 20 anos.

${ }^{4}$ Em 2010 o Censo Demográfico somente identificou relações de parentesco com o responsável pelo domicílio, abandonando a identificação de núcleos reprodutivos e, consequentemente, o termo família.
} 
- em cada $t=1,3,5, \ldots$, é feita a seguinte multiplicação:

$$
\begin{aligned}
& \hat{m}_{i j}^{(t)}=\hat{m}_{i j}^{(t-1)}\left(\frac{100}{\hat{m}_{i+}^{(t-1)}}\right) \\
& \mathrm{e} \\
& \hat{m}_{i j}^{(t+1)}=\hat{m}_{i j}^{(t)}\left(\frac{100}{\hat{m}_{+j}^{(t)}}\right)
\end{aligned}
$$

- essa multiplicação é repetida quantas vezes forem necessárias até se obterem os totais marginais em cada linha e coluna iguais a 100.

Ao cabo desses procedimentos, a tabela estará padronizada e todas as demais análises poderão ser feitas. No âmbito do presente estudo, foram calculadas as proporções padronizadas de cada união e, a partir delas, a taxa geral de endogamia - TGE (soma de todas as uniões endogâmicas dividida pelo total de uniões), ${ }^{5}$ considerando-se a raça/cor da mulher e a do homem (branca, preta, parda, amarela ou indígena), a idade da mulher (20 a 29 , 30 a 49 e 50 anos ou mais), o tipo da união (unidas ou casadas), a situação do domicílio (urbano ou rural) e o tipo de município de residência (se o município contém TI ou não).

Ao se calcularem as taxas de endogamia, têm-se, por conseguinte, as taxas de exogamia, pois são complementares (ou seja, o somatório deve ser sempre igual a 100). Isso significa que a análise comparativa dos valores permite decompor as uniões do ponto de vista da seletividade marital por raça/cor. ${ }^{6}$

\section{Procedimentos adicionais}

Para a análise da endogamia, foi identificado inicialmente o montante de mulheres de 15 anos ou mais que declararam estar em união, tanto para as indígenas quanto para as não indígenas (brancas, pretas, amarelas e pardas). Portanto, a primeira exclusão de casos foi de mulheres sem declaração de união e sem declaração de raça/cor. Com relação à idade, todas as mulheres forneceram esta informação, mas foram excluídas aquelas com cônjuge com idade inferior a 15 anos.

Dada a maior dificuldade de uso da informação sobre localização do cônjuge/companheiro, necessária para identificar os casais, optou-se por trabalhar com o dado tipo de arranjo familiar, ${ }^{7}$ para a identificação dos casais. Este procedimento implicou a exclusão de algumas mulheres unidas, por estarem em arranjos nos quais não foi possível verificar as características dos respectivos cônjuges/companheiros. A variável relação de parentesco com o responsável pelo domicílio permite identificar de forma direta a mulher e seu

\footnotetext{
${ }^{5}$ Para mais detalhes, ver Oliveira (2006).

${ }^{6}$ Algumas variáveis são muito importantes para a análise das uniões, como a escolaridade e a religião (LONGO, 2011, 2014). No entanto, como o foco deste estudo é a população indígena e essas variáveis devem ser olhadas com cautela nessa população, optou-se por não incluí-las na análise.

${ }^{7}$ A informação sobre localização do companheiro/cônjuge foi uma das variáveis utilizadas pelo IBGE para calcular o tipo de família, variável auxiliar disponível na amostra dos microdados do Censo, visto que a informação sobre relação de parentesco com o responsável pela família não foi incluída no questionário do Censo 2010, mas somente a relação de parentesco com o responsável pelo domicílio/oca.
} 
cônjuge para as famílias primárias. No caso das famílias secundárias (conviventes), somente foi possível identificar o cônjuge da mulher que morava fora de Terras Indígenas, uma vez que os dados divulgados pelo IBGE não incluem a identificação de família em unidades domésticas localizadas em TI (IBGE, 2010). Isso ocorreu porque a variável de localização do companheiro/cônjuge apresentou problemas na coleta de dados com o dispositivo móvel de captura de dados para setores censitários localizados em Terras Indígenas, como descrito no informe metodológico do Censo (IBGE, 2013), impedindo que se identifique o cônjuge/ companheiro de mulheres unidas que não sejam a responsável ou a cônjuge no domicílio/ oca. Assim, devido ao perfil residencial de populações indígenas, muito diferenciado das não indígenas, que, em geral, residem em domicílios com somente um núcleo reprodutor (família), a perda é considerável. Essa é uma questão que merece atenção, pois implica que não se pode conduzir a análise de homogamia para grande parcela das mulheres indígenas, como mostrado na seção de resultados, que exclui todas as mulheres casadas que não eram chefe ou cônjuge/companheira residentes em TI. Ou seja, a análise de homogamia indígena apresenta seletividade grande, visto que as mulheres indígenas incluídas na análise podem apresentar comportamento muito diferenciado daquelas que foram excluídas do estudo.

\section{Resultados}

Idade média à união (SMAM - Singulate Mean Age at Marriage)

Os resultados apresentados na Tabela 1 mostram que os indígenas têm a menor idade média à união, tanto para as mulheres ( 20,25 anos) quanto para os homens ( 23,72 anos) do que as demais categorias de raça/cor. No caso da idade média ao casar no civil e/ou religioso, os homens indígenas também apresentaram os menores valores de SMAM, embora para as mulheres esse mesmo padrão não se verifica, pois as mulheres brancas e amarelas têm uma SMAM inferior à das indígenas. Esse resultado pode estar associado ao fato de que os casamentos formalizados são menos frequentes entre as indígenas, principalmente entre as mais jovens.

Considerando-se apenas as pessoas que se declararam ${ }^{8}$ indígenas no Censo Demográfico, podemos estender essa análise para aqueles que moram em áreas urbanas e rurais e os residentes em municípios que contêm ou não Terras Indígenas. Os resultados mostram que as menores idades médias à união ocorrem em áreas rurais e em municípios com Terras Indígenas. Nesse caso, tal resultado corrobora o fato de que a união indígena acontece precocemente e guarda relação direta com a localização desses indígenas. Quanto ao casamento formal, nota-se o mesmo padrão revelado pela idade média à união, com destaque para as áreas rurais, com indígenas que apresentam idades médias inferiores às dos indígenas residentes em municípios com Terras Indígenas.

\footnotetext{
8 É importante destacar que apenas $35 \%$ das informações de raça/cor prestadas no Censo Demográfico foram dadas pela própria pessoa, portanto, estamos falando mais de alterdeclaração do que de autodeclaração. No entanto, como essa variável não foi incluída nesse estudo, considera-se a informação de raça/cor como autodeclaração.
} 
TABELA 1

Idade média (1) à união e ao casamento formalizado, por sexo, segundo características populacionais selecionadas

Brasil - 2010

\begin{tabular}{lccccc}
\hline \multirow{2}{*}{ Características selecionadas } & \multicolumn{2}{c}{ Idade média à união } & & \multicolumn{2}{c}{$\begin{array}{c}\text { Idade média ao casamento } \\
\text { civil/religioso }\end{array}$} \\
\cline { 2 - 3 } \cline { 5 - 6 } \cline { 5 - 6 } Total & Mulheres & Homens & & Mulheres & Homens \\
\cline { 5 - 6 } Brancos & 22,95 & 25,96 & & 29,68 & 31,95 \\
Pretos & 23,57 & 26,47 & & 29,13 & 31,59 \\
Amarelos & 22,68 & 25,11 & & 30,63 & 32,03 \\
Pardos & 22,15 & 25,86 & & 29,10 & 31,53 \\
Indígenas & 22,43 & 25,64 & & 30,06 & 32,19 \\
Residentes em municípios com TI & 20,25 & 23,72 & & 29,74 & 31,37 \\
Residentes em municípios sem TI & 20,17 & 23,27 & & 28,96 & 30,02 \\
Residentes em área urbana & 20,85 & 24,67 & & 29,85 & 31,92 \\
Residentes em área rural & 20,91 & 24,69 & & 30,22 & 32,24 \\
\hline
\end{tabular}

Fonte: IBGE, Censo Demográfico 2010, microdados da amostra.

(1) Elaborada de acordo com metodologia descrita em Newell (1988).

Após identificar a média de idade às uniões (formais e informais), outra análise se torna necessária: conhecer como se dão essas uniões, do ponto de vista da endogamia/ exogamia da raça/cor e considerando características importantes como idade, situação do domicílio e tipo do município de residência.

\section{Perfil das uniões}

A Tabela 2 traz uma caracterização das mulheres incluídas e não incluídas na análise de homogamia, segundo grupos etários e situação do domicílio, além de indicar as taxas de perda (mulheres excluídas da análise). Como mencionado, a grande perda se dá para as mulheres residentes em Terras Indígenas, onde a localização do companheiro/cônjuge não está disponível, resultando em mais de $80 \%$ de exclusão das mulheres indígenas da análise. Adicionalmente, como se pode observar, as taxas de perda de casos por idade ocorreram mais para a população indígena do que para a não indígena, sendo ainda maiores para as idades mais novas.

As indígenas da área rural também são as que apresentam o menor percentual de nunca unidas nas idades de 15 a 19 anos. Entre as não indígenas, destacam-se as baixas taxas de perda de casos nas áreas rurais. Além disso, a maior proporção de nunca unidas dos 15 a 19 anos é encontrada nas áreas urbanas.

A análise da homogamia por raça/cor, portanto, inclui mulheres de 20 anos ou mais, casadas ou unidas, sem informações ignoradas e em arranjos nos quais foi possível identificar o parceiro, totalizando 38.258.421 mulheres (na amostra expandida). Desse total, a maioria é casada $(65,4 \%)$, mora em área urbana $(84,2 \%)$. A maior parte $(50,2 \%)$ está no grupo etário de 30 a 49 anos. 
TABELA 2

Mulheres incluídas e não incluídas nas análises de homogamia por raça/cor, por situação do domicílio, segundo grupos de idade

Brasil - 2010

\begin{tabular}{|c|c|c|c|c|c|}
\hline \multirow[b]{2}{*}{$\begin{array}{l}\text { Grupos de idade } \\
\quad \text { (em anos) }\end{array}$} & \multicolumn{5}{|c|}{ Urbano } \\
\hline & $\begin{array}{l}\text { Total de } \\
\text { mulheres }\end{array}$ & Unidas & $\begin{array}{l}\text { Total de mulheres } \\
\text { incluídas na } \\
\text { análise }\end{array}$ & $\begin{array}{c}\text { Taxa de } \\
\text { perda (\%) }\end{array}$ & $\begin{array}{c}\% \text { de nunca } \\
\text { unidas }\end{array}$ \\
\hline \multicolumn{6}{|l|}{ Indígenas } \\
\hline $15-19$ & 14.313 & 3.090 & - & - & 72,32 \\
\hline $20-29$ & 27.988 & 16.078 & 14.599 & 9,20 & 27,50 \\
\hline $30-49$ & 64.045 & 33.933 & 32.022 & 5,63 & 6,74 \\
\hline 50 e mais & 40.296 & 16.917 & 15.882 & 6,12 & 6,39 \\
\hline \multicolumn{6}{|l|}{ Não indígenas } \\
\hline $15-19$ & 7.025 .066 & 954.692 & - & - & 82,62 \\
\hline $20-29$ & 14.950 .539 & 7.329 .840 & 7.114 .489 & 2,94 & 40,17 \\
\hline $30-49$ & 24.405 .749 & 16.762 .958 & 16.352 .227 & 2,45 & 11,90 \\
\hline 50 e mais & 18.272 .643 & 8.867 .788 & 8.691 .727 & 1,99 & 7,79 \\
\hline & \multicolumn{5}{|c|}{ Rural } \\
\hline $\begin{array}{l}\text { Grupos de idade } \\
\quad \text { (em anos) }\end{array}$ & $\begin{array}{l}\text { Total de } \\
\text { mulheres }\end{array}$ & Unidas & $\begin{array}{c}\text { Total de mulheres } \\
\text { incluídas na } \\
\text { análise }\end{array}$ & $\begin{array}{c}\text { Taxa de } \\
\text { perda (\%) }\end{array}$ & $\begin{array}{c}\% \text { de nunca } \\
\text { unidas }\end{array}$ \\
\hline \multicolumn{6}{|l|}{ Indígenas } \\
\hline $15-19$ & 26.328 & 9.210 & - & - & 59,95 \\
\hline $20-29$ & 38.829 & 27.281 & 4.260 & 84,39 & 21,72 \\
\hline $30-49$ & 59.670 & 34.719 & 6.533 & 81,18 & 4,33 \\
\hline 50 e mais & 25.166 & 15.712 & 3.601 & 77,08 & 5,07 \\
\hline \multicolumn{6}{|l|}{ Não indígenas } \\
\hline $15-19$ & 1.362 .292 & 282.898 & - & - & 75,78 \\
\hline $20-29$ & 2.236 .851 & 1.437 .085 & 1.408 .942 & 1,96 & 27,86 \\
\hline $30-49$ & 3.475 .541 & 2.865 .677 & 2.818 .345 & 1,65 & 7,35 \\
\hline 50 e mais & 2.778.018 & 1.819 .621 & 1.795 .794 & 1,31 & 5,40 \\
\hline
\end{tabular}

Fonte: Censo Demográfico 2010, microdados da amostra.

Em relação às indígenas, a maioria também é casada (51,7\%), mora em área urbana $(81,3 \%)$ e $50,1 \%$ também estão no grupo etário de 30 a 49 anos.

Esses resultados mostram que a população autodeclarada indígena tem características diferenciadas dos totais de população, pois, mesmo sendo um grupo percentualmente pequeno, é nítida a sobrerrepresentação em termos proporcionais da população indígena entre as mulheres em união consensual, moradoras em áreas rurais (Tabela 1 do Anexo), características que seriam ainda mais distintas se todas as mulheres indígenas residentes em TI tivessem sido incluídas na análise.

Quando se analisa a distribuição percentual das uniões por raça/cor dos cônjuges, encontra-se uma distribuição que sofre influência direta do tamanho dos grupos de raça/ cor, como pode ser visualizado na Tabela 3, que apresenta os dados conforme observados e os padronizados. Os percentuais para uniões de amarelos e indígenas são todos abaixo de $1,0 \%$, refletindo a proporção desses segmentos na população brasileira. Assim, fica evidenciada a necessidade de padronizar os dados, como já mencionado na metodologia. 
Nesse caso, todos os resultados apresentados e discutidos nesta seção foram realizados com base na distribuição padronizada, ou seja, considerando-se hipoteticamente que todos os grupos de raça/cor tivessem o mesmo tamanho, sendo possível analisar como ocorreriam as uniões entre esses grupos. Com base nessa distribuição percentual padronizada, também é possível calcular as taxas de endogamia e exogamia.

Os dados padronizados mostram que a maior endogamia por raça/cor é encontrada entre os indígenas $(91,5 \%)$. Isso significa que de todas as uniões em que pelo menos uma pessoa é indígena, em $91,5 \%$ delas ocorre a união entre dois indígenas, independentemente da etnia específica de cada um deles. Nenhuma outra categoria de raça/cor atingiu uma endogamia tão forte, sendo verificados $62,0 \%$ para branca, $67,8 \%$ para preta, $82,7 \%$ para amarela e 59,0\% para parda (Tabela 3 ).

Como já apontado anteriormente, é necessário analisar essa informação com cautela. Essa expressiva endogamia é observada quando se considera apenas a declaração de raça/ cor. Dentro desse grupo de indígenas endogâmicos, encontram-se indivíduos de etnias diferentes ou que falam línguas distintas. Nesse caso, é possível que, do ponto de vista da antropologia, sejam incluídos casais exogâmicos. No entanto, como não é possível nesse momento trabalhar tais informações, a análise aqui realizada sobre uniões endogâmicas/ exogâmicas entre indígenas considera a endogamia/exogamia por raça/cor declarada, ou seja, a união entre indígenas e as demais categorias de raça/cor.

TABELA 3

Distribuição não padronizada e padronizada das uniões (1), segundo raça/cor dos casais Brasil - 2010

Em porcentagem

\begin{tabular}{|c|c|c|c|c|c|c|}
\hline \multirow{2}{*}{$\begin{array}{l}\text { Raça/cor do } \\
\text { homem }\end{array}$} & \multicolumn{6}{|c|}{ Raça/cor da mulher } \\
\hline & Branca & Preta & Amarela & Parda & Indígena & Total \\
\hline \multicolumn{7}{|l|}{ Não padronizada } \\
\hline Branco & 37,3 & 1,8 & 0,3 & 10,0 & 0,1 & 49,4 \\
\hline Preto & 2,3 & 3,5 & 0,1 & 2,8 & 0,0 & 8,6 \\
\hline Amarelo & 0,3 & 0,1 & 0,5 & 0,3 & 0,0 & 1,1 \\
\hline Pardo & 10,6 & 1,6 & 0,4 & 28,0 & 0,0 & 40,7 \\
\hline Indígena & 0,1 & 0,0 & 0,0 & 0,0 & 0,1 & 0,2 \\
\hline Total & 50,5 & 6,9 & 1,3 & 41,1 & 0,2 & 100,0 \\
\hline \multicolumn{7}{|l|}{ Padronizada } \\
\hline Branco & 62,0 & 12,2 & 4,3 & 18,8 & 2,7 & 100,0 \\
\hline Preto & 10,7 & 67,8 & 5,2 & 14,5 & 1,8 & 100,0 \\
\hline Amarelo & 4,8 & 5,6 & 82,7 & 5,4 & 1,4 & 100,0 \\
\hline Pardo & 19,9 & 12,4 & 6,3 & 59,0 & 2,5 & 100,0 \\
\hline Indígena & 2,6 & 2,0 & 1,6 & 2,3 & 91,5 & 100,0 \\
\hline Total & 100,0 & 100,0 & 100,0 & 100,0 & 100,0 & \\
\hline Total valor absoluto & 19.332 .503 & 2.629 .894 & 479.877 & 15.739 .249 & 76.897 & 38.258 .421 \\
\hline
\end{tabular}

Fonte: IBGE. Censo Demográfico 2010, microdados da amostra.

(1) Uniões com mulheres de 20 anos ou mais de idade e não inclui casais residentes em Terras Indígenas que não eram o responsável ou o cônjuge/companheiro no domicílio/oca. 
Outras diferenças nas proporções das uniões por raça/cor começam a aparecer quando se analisam separadamente o tipo de união, a situação do domicílio e se o município de residência possui ou não Terra Indígena (Tabela 2 do Anexo).

Em relação ao tipo de união, percebe-se que a endogamia é maior entre as casadas (64,1\% para brancas, $71,0 \%$ para pretas, $84,8 \%$ para amarelas, $61,1 \%$ para pardas e $92,0 \%$ para indígenas) do que entre as unidas (56,7\%, 61,9\%, 77,0\%, 54,8\% e $90,6 \%$, respectivamente). Note-se que a menor diferença se dá entre as indígenas, provavelmente devido ao alto grau de endogamia.

Considerando a situação do domicílio, encontram-se diferenças importantes que mostram que a endogamia é mais presente em áreas rurais (66,8\% para brancas, $70,7 \%$ para pretas, $81,1 \%$ para amarelas, $61,3 \%$ para pardas e $96,4 \%$ para indígenas) em relação às áreas urbanas $(61,0 \%, 67,0 \%, 82,8 \%, 58,1 \%$ e $89,9 \%$, respectivamente). A exceção, nesse caso, são os autodeclarados amarelos. De toda forma, as maiores proporções de uniões endogâmicas também são encontradas entre os indígenas.

Os municípios que contêm Terras Indígenas também concentram as maiores proporções de uniões endogâmicas por raça/cor, mesmo entre os não indígenas. Ainda assim, nesses municípios são encontrados os maiores percentuais de endogamia por raça/cor entre os indígenas (93,6\%).

A partir dessa distribuição percentual das uniões, é possível calcular as taxas de endogamia e exogamia dessas populações por faixas de idade das mulheres. Assim, pode-se analisar uma medida sintética que traz informações importantes para conhecer como se dão as uniões entre as diferentes coortes.

A Tabela 4 traz as taxas de endogamia e exogamia calculadas a partir da distribuição percentual das uniões por raça/cor dos parceiros. As taxas de endogamia por raça/cor mostram três questões importantes para o tema discutido neste trabalho.

A primeira é a relação da endogamia com as características investigadas, pois as maiores taxas de endogamia são encontradas entre as pessoas casadas, em áreas rurais e em municípios com Terras Indígenas. Esse resultado ressalta a relevância da raça/cor para as uniões formalizadas e em locais que podem dar mais importância à formalização da união.

A segunda questão é a relação encontrada entre as taxas de endogamia e as faixas de idade selecionadas para as mulheres. Para aquelas de 20 anos ou mais, quanto maior a faixa de idade analisada, maior é a endogamia. Esse resultado também corrobora o ponto destacado acima, pois mulheres mais velhas podem ter maiores dificuldades de transpor as barreiras que resultem em casamentos inter-raciais.

A terceira questão trata da endogamia indígena, que é muito mais alta do que para o conjunto dos casais com mulheres de 20 anos ou mais. No caso dos indígenas, apesar de quase todas as taxas serem acima de $90 \%$, há também uma propensão maior para a endogamia entre as casadas formalmente, moradoras de áreas rurais e em municípios com Terras Indígenas. A diferença, nesse caso, aparece em relação aos grupos de idade investigados, sendo encontradas taxas de endogamia ligeiramente menores para o grupo 
de mulheres de 30 a 49 anos entre as unidas, moradoras de áreas urbanas e em municípios sem Terra Indígena. Esse resultado chama mais atenção porque as indígenas mais novas (20 a 29 anos) nesses grupos possuem taxas um pouco superiores.

\section{TABELA 4}

Taxas de endogamia e exogamia por raça/cor, segundo grupos de idade, condição marital (1), situação do domicílio e tipo do município

Brasil - 2010

Em porcentagem

\begin{tabular}{lcccc}
\hline \multicolumn{1}{c}{ Grupos de idade (em anos) e } & $\begin{array}{c}\text { Taxa geral de } \\
\text { endogamia (2) }\end{array}$ & $\begin{array}{c}\text { Taxa geral de } \\
\text { exogamia (2) }\end{array}$ & $\begin{array}{c}\text { Taxa de } \\
\text { endogamia } \\
\text { indígena (3) }\end{array}$ & $\begin{array}{c}\text { Taxa de } \\
\text { exogamia } \\
\text { indígena (4) }\end{array}$ \\
\hline Total & 61,5 & 38,5 & 91,5 & 8,5 \\
20-29 & 57,7 & 42,3 & 91,8 & 8,2 \\
30-49 & 60,0 & 40,0 & 90,9 & 9,1 \\
50 e mais & 66,7 & 33,3 & 92,3 & 7,7 \\
\hline Casadas & 63,7 & 36,3 & 92,0 & 8,0 \\
20-29 & 58,6 & 41,4 & 92,0 & 8,0 \\
30-49 & 61,9 & 38,1 & 91,6 & 8,4 \\
50 e mais & 68,2 & 31,8 & 92,4 & 7,6 \\
\hline Unidas & 56,6 & 43,4 & 90,6 & 9,4 \\
20-29 & 56,7 & 43,3 & 91,5 & 8,5 \\
30-49 & 56,1 & 43,9 & 89,7 & 10,3 \\
50 e mais & 58,3 & 41,7 & 91,1 & 8,9 \\
\hline Área urbana & 60,6 & 39,4 & 89,9 & 10,1 \\
20-29 & 56,9 & 43,1 & 90,1 & 9,9 \\
30-49 & 59,1 & 40,9 & 89,2 & 10,8 \\
50 e mais & 65,9 & 34,1 & 90,8 & 9,2 \\
\hline Área rural & 64,4 & 35,6 & 96,4 & 3,6 \\
20-29 & 60,4 & 39,6 & 96,2 & 3,8 \\
30-49 & 63,6 & 36,4 & 96,3 & 3,7 \\
50 e mais & 68,5 & 31,5 & 96,5 & 3,5 \\
\hline Residentes em municípios com Terras & 63,2 & 36,8 & 93,6 & 6,4 \\
Indígenas & 57,7 & 42,3 & 93,1 & 6,9 \\
20-29 & 61,6 & 38,4 & 93,1 & 6,9 \\
30-49 & 69,3 & 30,7 & 94,6 & 5,4 \\
50 e mais & 60,9 & 39,1 & 89,5 & 10,5 \\
\hline Residentes em municípios sem Terras & 57,5 & 42,5 & 89,7 & 10,3 \\
Indígenas & 59,4 & 40,6 & 88,6 & 11,4 \\
20-29 & 66,0 & 34,0 & 90,7 & 9,3 \\
30-49 & & & & \\
50 e mais & 6,3 & \\
\hline
\end{tabular}

Fonte: Censo Demográfico 2010, microdados da amostra.

(1) Uniões com mulheres de 20 anos ou mais de idade e não inclui casais residentes em Terras Indígenas que não eram o responsável ou o cônjuge/companheiro no domicilio/oca.

(2) Inclui todas as categorias de raça/cor.

(3) Ambos os cônjuges são indígenas.

(4) Apenas um dos cônjuges é indígena.

Vale destacar que o Censo de 2010 registrou, pela primeira vez, situações de poliginia entre os indígenas, com a possibilidade de uma mulher ter sido associada a um mesmo cônjuge/companheiro já associado a outra mulher. Assim, foram encontrados casos de 
poliginia em uniões indígenas com 2 e 3 cônjuges residentes em um mesmo domicílio. Por ser um número muito pequeno de casos e a expansão da amostra traria resultados com coeficientes de variação muito altos, optou-se por não analisar essas uniões no presente trabalho. ${ }^{9}$

Ainda que haja limitações na análise dos indígenas em razão das restrições metodológicas já mencionadas neste trabalho, os resultados aqui apresentados mostram que a população indígena tem características próprias em relação à nupcialidade e à formação das uniões. Tais aspectos serão discutidos na seção final deste trabalho.

\section{Discussão}

Há uma ampla literatura em antropologia que trata de aspectos socioculturais que influenciam a configuração da nupcialidade indígena a partir de uma abordagem qualitativa e localmente situada (MELATTI, 1987; VIVEIROS DE CASTRO, 1995). Apesar da grande contribuição desses estudos para a compreensão dos padrões de união (e cabe indicar que o conceito de nupcialidade não é frequentemente utilizado nos estudos etnológicos), a análise dos dados censitários acerca das uniões pode ajudar a evidenciar tendências e aspectos mais abrangentes, do ponto de vista dos estudos de população, sobre a nupcialidade das populações indígenas no Brasil.

Nesse sentido, os dados do Censo Demográfico 2010 constituem uma importante fonte que, com representatividade nacional, permite estudar os padrões de uniões segundo raça/cor no Brasil. Apesar dos problemas com os dados, esta análise é a mais aprofundada acerca dos perfis de nupcialidade de indígenas em comparação com outras categorias de raça/cor já conduzida com base em dados censitários no país, com o intuito de mostrar a potencialidade das análises possíveis, ainda que com as limitações impostas, tanto pela forma de coleta e divulgação dos dados, como por erros de levantamento de dados. Para tanto, foram calculadas as idades médias ao casamento formal e à união e também taxas de endogamia e exogamia por raça/cor para diversos grupos populacionais, considerando-se os grupos etários, situação do domicílio e tipo de município de residência, características importantes para a formação das uniões.

Vale reiterar a necessidade de analisar os dados censitários sobre nupcialidade indígena com extrema cautela devido às já aludidas limitações intrínsecas às categorias censitárias. Nesse sentido, noções como "união formal” e "união informal” são limitadas para captar as especificidades e multiplicidades dos arranjos matrimoniais presentes nas sociedades indígenas no Brasil. Como amplamente descrito na literatura

\footnotetext{
9 Nesse ponto cabe um esclarecimento da forma como foi coletada essa informação: o questionário permitia registrar para as mulheres, na pergunta sobre quem vivia em companhia de cônjuge ou companheiro, o nome deste e quando residia no mesmo domicílio, anotou-se o número de ordem na lista de pessoas residentes no domicílio. Cabe indicar que, na fase de crítica dos dados censitários por parte do IBGE, registros de homens com mais de um cônjuge para a população não indígena foram tratados como erros de registro e eliminados da base de dados, no entanto, esta informação está disponível somente para mulheres residentes fora de Terra Indígena, pelos problemas de coleta apontados anteriormente.
} 
antropológica, a questão da "formalização" de casamentos nessas sociedades segue critérios próprios, cuja diversidade não é abarcada na dicotomia formal/informal (MELLATI, 1987; SEEGER, 1980; VIVEIROS DE CASTRO, 1995). O conceito de informalidade pode, inclusive, ser distinto para os indivíduos. A partir dos dados coletados pelo Censo 2010, uma união não formalizada (consensual) baseia-se unicamente na ausência do casamento civil e/ou religioso para os casais que moram juntos. No entanto, os graus de comprometimento para essas uniões podem variar e essa é uma informação bastante subjetiva e não passível de ser captada. Mesmo assim, é somente dessa forma, considerando tal dicotomia, que se pode conhecer as uniões a partir dos dados censitários, ainda que não seja rigorosamente representativa, principalmente, de parte das uniões indígenas.

Nos últimos anos houve um expressivo incremento nas pesquisas sobre demografia dos povos indígenas a partir de dados censitários (AZEVEDO, 2011; PAGLIARO et al., 2005; IBGE, 2012a; SANTOS; TEIXEIRA, 2011). Além de análises voltadas para a caracterização de dinâmicas demográficas propriamente, têm sido realizadas investigações que analisam criticamente como são captados os dados censitários para os indígenas, com atenção para a influência de fatores socioeconômicos e culturais (PEREIRA et al., 2005, 2009; SANTOS et al., 2015). Nessa linha, Santos et al. (2015) analisaram dados do Censo 2010 sobre parturição de mulheres das Regiões Norte e Nordeste e observaram que as indígenas residentes na área rural do Norte apresentaram as mais elevadas proporções de respostas não providas pela própria mulher, o que pode ter ocorrido devido a dificuldades de coleta dos dados em função de diferenças linguísticas e do fato de as informações serem prestadas por pessoas que não conheciam suficientemente bem a história reprodutiva das mulheres. Na vertente de combinar criticamente questões ligadas à produção e análise de dados censitários referentes aos indígenas no Brasil, esse trabalho se defrontou com desafios conceituais e metodológicos enormes.

Mesmo diante dessas diversas limitações, é bastante chamativo que os padrões observados na presente investigação guardam proximidade com cenários descritos em etnografias que, ainda que não de uma vertente demográfica propriamente, abordaram o tema do casamento e com os poucos estudos de vertente demográfico-antropológica realizados em comunidades indígenas específicas (AZEVEDO, 2005; COIMBRA et al., 2002; MELATTI, 1987). Nesse sentido, os resultados sugerem que a idade média à união dos indígenas é a menor entre todas as categorias de raça/cor. Além disso, a idade média à união dessa população é menor em áreas rurais e em municípios que contêm Terras Indígenas. Ainda que não seja possível generalizar, diversos estudos etnológicos e em antropologia demográfica realizados em comunidades indígenas específicas indicam que é comum as mulheres se casarem bastante jovens, inclusive na faixa de 10 a 15 anos de idade (AZEVEDO, 2005; COIMBRA et al., 2002; MELATTI, 1987; TASSINARI, 1995).

A constatação de que os dados censitários também indicam elevadas taxas de "endogamia” em indígenas, no sentido de casamento nos quais ambos os cônjuges são 
de uma mesma categoria de cor ou raça, é igualmente condizente com outras análises recentes sobre demografia indígena (PAGLIARO et al., 2005). A maior tendência às uniões entre indígenas, verificada tanto em áreas rurais quanto urbanas, pode indicar um processo de manutenção da identidade étnica e de reprodução sociocultural dos povos indígenas no Brasil. Para confirmar essa hipótese, se faz necessária a realização de pesquisas demográficas específicas para a população indígena, que não devem se restringir aos censos decenais. Tais investigações poderiam prover informações relevantes com vistas à maior adequação dos instrumentos de coleta de dados, inclusive os utilizados nos censos nacionais, de modo a permitir que o mesmo possa captar as especificidades socioculturais e de relações interétnicas que configuram a nupcialidade entre os povos indígenas.

Ainda com respeito à questão da "endogamia", podem ser informativos os resultados de análises recentes sobre a composição dos domicílios segundo raça/cor a partir do Censo 2010. Marinho (2015) investigou a composição dos domicílios no Brasil segundo recorte de raça/cor e observou as mais elevadas frequências de homogeneidade para indígenas. Para o Brasil como um todo, urbano e rural combinados, $73,0 \%$ dos indígenas viviam em domicílios nos quais todos os outros residentes eram também indígenas. $\mathrm{Na}$ situação rural, as proporções para indígenas foram superiores a $90 \%$ em todas as regiões, alcançando $95,2 \%$ no Norte e $96,6 \%$ no Centro-Oeste. Ou seja, as taxas de "endogamia" no tocante à raça/cor na população parecem se vincular a particularidades de composição dos domicílios indígenas, marcadamente mais homogêneos por raça/cor se comparados aos não indígenas.

Na condução da presente investigação não foram consideradas dimensões usualmente exploradas em pesquisas sobre nupcialidade que exploram questões de endogamia versus exogamia. Temáticas como escolaridade e religião têm sido apontadas como importantes questões que influenciam a escolha de parceiros no Brasil (LONGO, 2011, 2015; RIBEIRO; SILVA, 2009). Levando em conta as particularidades que envolvem a definição e captação de dados censitários sobre pertencimento religioso (PISSOLATO, 2013), optou-se por não explorar essa variável no presente estudo. Não obstante, e sem dúvida, seria importante investigar os padrões de nupcialidade indígena considerando-se uma gama de fatores mais ampla, principalmente pertencimento étnico e línguas faladas, o que foi coletado no Censo 2010 para os indígenas. Uma proposta de análise futura seria utilizar os dados do universo de forma desagregada em paralelo com os dados da amostra do Censo Demográfico. Para isso, seria necessário o acesso a esses dados via procedimento específico exigido pelo IBGE para esse tipo de estudo, que é feito em sala de sigilo. ${ }^{10}$ Para elaborar essa análise, torna-se necessária a interface entre demografia e antropologia, de modo a identificar as possíveis endogamias étnicas e linguísticas.

\footnotetext{
${ }^{10}$ A sala de sigilo permite acesso aos microdados do universo, de forma desagregada. Porém, toda análise é feita em ambiente controlado, sem acesso à internet ou formas de cópia dos dados, sendo que os resultados são submetidos a um comitê avaliador para sua liberação para publicação, de modo a garantir o sigilo dos dados.
} 
Em conclusão, a principal contribuição deste trabalho foi avançar nos estudos sobre a demografia dos povos indígenas a partir dos resultados apresentados sobre a nupcialidade indígena a partir do Censo Demográfico. Embora com limitações metodológicas, foi possível analisar as uniões indígenas sob a perspectiva demográfica, trazendo à discussão os aspectos da nupcialidade que fogem à análise unicamente dos dados censitários. Mesmo com uma análise das uniões indígenas menos abrangente, devido ao fato de que não é toda a população indígena que está sendo analisada e que há dados importantes que não foram considerados, como o pertencimento étnico e as línguas faladas, este estudo é pioneiro no conhecimento da nupcialidade indígena e na caracterização de certos perfis de união entre indígenas e demais categorias de raça/cor, pelo menos do ponto de vista demográfico. Ainda assim, a junção das visões demográfica e antropológica é fundamental para se avançar nos estudos da demografia indígena.

Os avanços na captação de informações para a população indígena realizados pelo Censo 2010 são inegáveis. Não obstante, como evidenciado neste artigo, a forma e a disponibilidade dos dados demográficos sobre os indígenas nos bancos de dados limitam algumas análises, como a da nupcialidade. É importante que o próximo Censo Demográfico traga essas mesmas informações e que sejam estudadas novas formas para divulgá-las juntamente com os demais dados da amostra, assim como será necessário fazer testes cognitivos e extensivos testes pilotos com o uso de novas tecnologias para que estas não interfiram de maneira negativa na captação dos dados de alguns segmentos populacionais na próxima rodada do Censo.

\section{Referências}

AGRESTI, A. Categorical data analysis. New York: John Wiley \& Sons, 1990.

AZEVEDO, M. M. Demografia dos povos indígenas do Alto Rio Negro/AM: um estudo de caso de nupcialidade e reprodução. Tese (Doutorado) - Universidade Estadual de Campinas - Unicamp, Campinas, 2003.

Demografia dos povos indígenas do Alto Rio Negro. Revista Brasileira de Estudos de População, Belo Horizonte, v. 11, n. 2, p. 235-244, 1994. Disponível em: 〈http://www.abep. org.brr. Acesso em: 24 nov. 2015.

O Censo 2010 e os povos indígenas. In: RICARDO, B.; RICARDO, F. (Org.). Povos indígenas no Brasil: 2006-2010. São Paulo: Instituto Socioambiental, 2011. p. 45-48.

. Povos indígenas no Alto Rio Negro: um estudo de caso de nupcialidade. In: PAGLIARO, H.; AZEVEDO, M. M.; SANTOS, R. V. (Org.). Demografia dos povos indígenas no Brasil. Rio de Janeiro: Fiocruz/Abep, 2005. p. 33-58.

COIMBRA JR., C. E. A.; FLOWERS, N. M.; SALZANO, F. M.; SANTOS, R. V. The Xavánte in transition: health, ecology and bioanthropology in Central Brazil. Ann Arbor: University of Michigan Press, 2002.

FU, V. K. Racial intermarriage pairings. Demography, Chicago, v. 38, n. 2, p. 147-160, May 2001. GULLICKSON, A. Education and black-white interracial marriage. Demography, Chicago, v. 43, n. 4, p. 673-689, Nov. 2006. 
HEY, D. Nuptiality. The Oxford Companion to family and local history. Oxford: Oxford University Press, 2008.

IBGE - Instituto Brasileiro de Geografia e Estatística. Tendências demográficas: uma análise dos indígenas com base nos resultados da amostra dos Censos Demográficos de 1991 e 2000. Rio de Janeiro: IBGE, 2005. Censo Demográfico: microdados. Rio de Janeiro: IBGE, 2010.

Os indígenas no Censo Demográfico 2010: primeiras considerações com base no quesito cor ou raça. Rio de Janeiro: IBGE, 2012a.

IBGE, 2012b.

Nupcialidade, fecundidade e migração: resultados da amostra. Rio de Janeiro:

Metodologia do Censo Demográfico 2010. Rio de Janeiro: IBGE, 2013.

LÉVI-STRAUSS, C. As estruturas elementares do parentesco. São Paulo: Editora Vozes, 1982.

LONGO, L. A. F. B. Uniões intra e interraciais, status marital, escolaridade e religião no Brasil: um estudo sobre a seletividade marital feminina, 1980-2000. Tese (Doutorado em Demografia) - Centro de Desenvolvimento e Planejamento Regional, Universidade Federal de Minas Gerais - Cedeplar/UFMG, Belo Horizonte, 2011.

Exogamia racial, educacional e religiosa: o papel do status marital. In: ENCONTRO NACIONAL DE ESTUDOS POPULACIONAIS, XIX. Anais... Caxambu: Abep, 2014. Disponível em: 〈http://abep.info/files/trabalhos/trabalho_completo/TC-8-32-481-485.pdf〉. Acesso em: 23 nov. 2015.

MARINHO, G. Domicílios indígenas nos Censos Demográficos: classificação, composição e interfaces com a saúde. Tese (Doutorado em Epidemiologia em Saúde Pública) - Escola Nacional de Saúde Pública, Fundação Oswaldo Cruz - Fiocruz, Rio de Janeiro, 2015.

MAYBURY-LEWIS, D. Dialectial societies: the Gê and Bororo of Central Brazil. Cambridge, MA: Harvard University Press, 1979.

MELATTI, J. C. Índios do Brasil. 5. ed. São Paulo: Hucitec; Brasília: Editora da Universidade de Brasília, 1987.

NEWELL, C. Methods and models in demography. New York: The Guilford Press, 1988.

OLIVEIRA, R. V. C. Modelos de Goodman para a análise de endogamia de cor: Brasil 2000. Dissertação (Mestrado em Estudos Populacionais e Pesquisas Sociais) - Escola Nacional de Ciências Estatísticas, IBGE, Rio de Janeiro, 2006.

PAGLIARO, H.; AZEVEDO, M. M.; SANTOS, R. V. Demografia dos povos indígenas no Brasil: um panorama crítico. In: PAGLIARO, H.; AZEVEDO, M. M.; SANTOS, R. V. (Org.). Demografia dos povos indígenas no Brasil. Rio de Janeiro: Fiocruz/Abep, 2005. p. 11-32.

PEREIRA, N. O. M.; AZEVEDO, M. M.; SANTOS, R. V. Perfil demográfico e socioeconômico das pessoas que se autodeclararam indígenas no Brasil. In: PAGLIARO, H.; AZEVEDO, M. M.; SANTOS, R. V. (Org.). Demografia dos Povos indígenas no Brasil. Rio de Janeiro: Fiocruz/Abep, 2005. p. 155-166.

PEREIRA, N. O. M.; SANTOS, R. V.; WELCH, J. R.; COIMBRA JR., C. E. A.; SOUZA, L. G. Demography, territory, and identity of indigenous peoples in Brazil: the Xavante indians and the 2000 Brazilian national census. Human Organization, v. 68, n. 2, p.166-180, 2009.

PETRUCELLI, J. L. Seletividade por cor e escolhas conjugais no Brasil dos 90. Estudos AfroAsiáticos, v. 23, n. 1, p. 30-51, 2001. 
PISSOLATO, E. Tradições indígenas nos censos brasileiros: questões em torno do reconhecimento indígena e da relação entre indígenas e religião. In: TEIXEIRA, F.; MENEZES, R. (Org.). Religiões em movimento: o Censo de 2010. Petrópolis: Vozes, 2013. p. 235-252.

POZZOBON, J. 0 mínimo demográfico de um sistema de metades exogâmicas (uma simulação em computador). Revista Brasileira de Estudos de População, v. 11, n. 2, p. 139-154, 1994.

QIAN, Z. Breaking the racial barriers: variations in interracial marriage between 1980 and 1990. Demography, Chicago, v. 34, n. 2, p. 263-276, May 1997.

RIBEIRO, C. A. C.; SILVA, N. V. Cor, educação e casamento: tendência da seletividade marital no Brasil, 1960 a 2000. Dados: Revista de Ciências Sociais, Rio de Janeiro, v. 52, n. 1, p. 7-51, 2009.

SHAPIRO, J. Marriage rules, marriage exchange, and the definition of marriage in Lowland South America societies. In: KENSINGER, K. M. (Ed.). Marriage practices in Lowland South America. Illinois Studies in Anthropology, n. 14. Urbana: University of Illinois Press, 1984. p. 1-30.

SANTOS, R. V.; BASTOS, J. L.; CRUZ, O. G.; LONGO, L. A. F.; FLOWERS, N. M.; PEREIRA, N. O. M. Parity of indigenous and non-indigenous women in Brazil: does the reported number of children born depend upon who answers national census questions? PLoS ONE, v. 10, n. 4, p. e0123826, 2015.

SEEGER, A. Os índios e nós: estudos sobre sociedades tribais brasileiras. Rio de Janeiro: Editora Campus, 1980.

SHRYOCK, H.; SIEGEL, J. S. The methods and materials of demography. San Diego: Academic Press, 1976.

TASSINARI, A. M. I. Sociedades indígenas: introdução ao tema da diversidade cultural. In: SILVA, A. L.; GRUPIONI, L. D. B. (Org.). A temática indígena na escola: novos subsídios para professores de $1^{\circ}$ e $2^{\circ}$ graus. Brasília: MEC/Unesco, 1995. p. 445-479.

TEIXEIRA, P. Sateré-Mawe: retrato de um povo indígena. Belém: Unicef/Fundo de População das Nações Unidas, 2005.

TELLES, E. E. Racismo à brasileira: uma nova perspectiva sociológica. Rio de Janeiro: Relume Dumará, 2003.

VIEIRA, J. M.; ALVES, L. C. Comportamento da nupcialidade no Brasil e nas unidades federativas em 2000 e 2010. In: ENCONTRO NACIONAL DE ESTUDOS POPULACIONAIS, XIX. Anais... Caxambu: Abep, 2014. Disponivel em: 〈http://abep.info/files/trabalhos/trabalho_completo/TC-8-32-131210.pdf>. Acesso em: 23 nov. 2015.

VIVEIROS DE CASTRO, E. (Org.). Antropologia do parentesco: estudos ameríndios. Rio de Janeiro: Editora UFRJ, 1995.

\section{Sobre as autoras}

Luciene Aparecida Ferreira de Barros Longo é doutora em Demografia pelo Centro de Desenvolvimento e Planejamento Regional da Universidade Federal de Minas Gerais (Cedeplar/ UFMG). Tecnologista em informações geográficas e estatísticas do Instituto Brasileiro de Geografia e Estatística (IBGE).

Luciane Ouriques Ferreira é doutora em Antropologia Social pela Universidade Federal de Santa Catarina, bolsista de pós-doutorado do Programa Brasil Sem Miséria/Capes na Escola Nacional de Saúde Pública/Fundação Oswaldo Cruz.

Marta Maria do Amaral Azevedo é doutora em Demografia pela Universidade Estadual de Campinas (Unicamp). Professora do Programa de Pós-Graduação em Demografia do Instituto 
de Filosofia e Ciências Humanas, Núcleo de Estudos de População, Universidade Estadual de Campinas (IFCH/Nepo/Unicamp), pesquisadora do Nepo.

\section{Endereço para correspondência}

Luciene Aparecida Ferreira de Barros Longo

Rua Oliveira, 523, Cruzeiro

30310-150 - Belo Horizonte-MG, Brasil

Luciane Ouriques Ferreira

Rua Riachuelo, 119, apto. 705, Lapa

20230-010 - Rio de Janeiro-RJ, Brasil

Marta Maria do Amaral Azevedo

Universidade Estadual de Campinas - Núcleo de Estudos de População, Cidade

Universitária Zeferino Vaz, Caixa Postal 6166, Barão Geraldo

13081-970 - Campinas-SP, Brasil 


\begin{abstract}
Nuptiality of indigenous people: possibilities and limitations of analyses using the Demographic Census of 2010
\end{abstract}

This paper analyzes nuptiality data from the Brazilian 2010 Demographic Census, with a focus on indigenous women. There is an extensive anthropological literature about the social organization of indigenous peoples in Brazil and its relation to marriage practices. Concerning the demographic field, however, very little is known about nuptiality in this segment of the population and how it compares with non-indigenous women. The objective is to present an analysis of nuptiality patterns, using the surveyed categories of race/color in the 2010 Census, focusing on indigenous population. The mean age of women at marriage and non formal union by race/ color and endogamy and exogamy rates are estimated, showing results stratified by age groups, marital status, place of residence urban or rural, and residents in municipalities with or without Indigenous Lands. Despite the evident data limitation, the results show that indigenous women present the lowest mean age at marriage, as well as the highest endogamy rates by race/color.

Keywords: Nuptiality. Indigenous peoples. Race/color. Demographic Census. Brazil.

\title{
Resumen
}

Nupcialidad de los indígenas: posibilidades y limitaciones de análisis utilizando datos del Censo Demográfico de 2010

Este artículo analiza los datos de nupcialidad del Censo Demográfico brasileño de 2010, con especial atención a las mujeres indígenas. Hay una extensa literatura antropológica sobre la organización social de los pueblos indígenas en Brasil y su relación con las prácticas matrimoniales. Cuando se trata de la demografía, sin embargo, se sabe muy poco acerca de la nupcialidad en este segmento de la población y cómo se compara con las mujeres no indígenas. El objetivo es presentar un análisis de los patrones de nupcialidad, utilizando las categorías de auto declaradas de raza/color de la piel en el Censo de 2010, centrándose en la población indígena. Se calcula la edad media a la unión formal y consensual y, también, las tasas de endogamia y exogamia por raza/color, con los resultados estratificados por grupos de edad, situación conyugal, área de residencia (rural o urbana) y domicilio en municipalidades con Tierras Indígenas. A pesar de las evidentes limitaciones de los datos, y el uso de métodos demográficos indirectos, los resultados muestran que, entre todas las categorías de raza/color, la edad media al matrimonio de los indígenas es la más baja y sus tasas estandarizadas de endogamia por raza/color son los más altas.

Palabras clave: Nupcialidad. Indígenas. Raza/color. Censo Demográfico. Brasil.

Recebido para publicação em 30/11/2015 Recomendado para publicação em 19/09/2016 Aceito para publicação em 04/11/2016 


\section{Anexo}

TABELA 1

Mulheres de 20 anos ou mais de idade, segundo grupos de idade, condição marital, situação do domicílio e tipo do município

Brasil - 2010

\begin{tabular}{|c|c|c|c|c|c|c|}
\hline $\begin{array}{c}\text { Grupos de idade (em anos), } \\
\text { condição marital, situação do domicílio } \\
\text { e tipo do município }\end{array}$ & Total & $\%$ & & Indígenas & $\%$ & \\
\hline Total & 38.258 .421 & 100,0 & & 76.897 & 100,0 & \\
\hline $20-29$ & 8.542 .290 & 22,3 & & 18.859 & 24,5 & \\
\hline $30-49$ & 19.209.127 & 50,2 & & 38.555 & 50,1 & \\
\hline 50 e mais & 10.507 .004 & 27,5 & & 19.483 & 25,3 & \\
\hline Casadas & 25.026 .249 & 65,4 & 100,0 & 39769 & 51,7 & 100,0 \\
\hline $20-29$ & 3.799 .585 & 9,9 & 15,2 & 6055 & 7,9 & 15,2 \\
\hline $30-49$ & 12.434 .824 & 32,5 & 49,7 & 19829 & 25,8 & 49,9 \\
\hline 50 e mais & 8.791 .839 & 23,0 & 35,1 & 13884 & 18,1 & 34,9 \\
\hline Unidas & 13.232 .172 & 34,6 & 100,0 & 37128 & 48,3 & 100,0 \\
\hline $20-29$ & 4.742 .705 & 12,4 & 35,8 & 12804 & 16,7 & 34,5 \\
\hline $30-49$ & 6.774 .303 & 17,7 & 51,2 & 18726 & 24,4 & 50,4 \\
\hline 50 e mais & 1.715 .164 & 4,5 & 13,0 & 5599 & 7,3 & 15,1 \\
\hline Área urbana & 32.220 .946 & 84,2 & 100,0 & 62503 & 81,3 & 100,0 \\
\hline $20-29$ & 7.129 .088 & 18,6 & 22,1 & 14599 & 19,0 & 23,4 \\
\hline $30-49$ & 16.384 .249 & 42,8 & 50,8 & 32022 & 41,6 & 51,2 \\
\hline 50 e mais & 8.707 .609 & 22,8 & 27,0 & 15882 & 20,7 & 25,4 \\
\hline Área rural & 6.037 .474 & 15,8 & 100,0 & 14393 & 18,7 & 100,0 \\
\hline $20-29$ & 1.413 .202 & 3,7 & 23,4 & 4260 & 5,5 & 29,6 \\
\hline $30-49$ & 2.824 .878 & 7,4 & 46,8 & 6533 & 8,5 & 45,4 \\
\hline 50 e mais & 1.799 .395 & 4,7 & 29,8 & 3601 & 4,7 & 25,0 \\
\hline $\begin{array}{l}\text { Residentes em municípios com Terras } \\
\text { Indígenas }\end{array}$ & 4.263 .022 & 11,1 & 100,0 & 25083 & 32,6 & 100,0 \\
\hline $20-29$ & 977.083 & 2,6 & 22,9 & 7330 & 9,5 & 29,2 \\
\hline $30-49$ & 2.154 .212 & 5,6 & 50,5 & 12463 & 16,2 & 49,7 \\
\hline 50 e mais & 1.131 .727 & 3,0 & 26,5 & 5290 & 6,9 & 21,1 \\
\hline $\begin{array}{l}\text { Residentes em municípios sem Terras } \\
\text { Indígenas }\end{array}$ & 33.995 .399 & 88,9 & 100,0 & 51814 & 67,4 & 100,0 \\
\hline $20-29$ & 7.565 .207 & 19,8 & 22,3 & 11529 & 15,0 & 22,3 \\
\hline $30-49$ & 17.054 .915 & 44,6 & 50,2 & 26092 & 33,9 & 50,4 \\
\hline 50 e mais & 9.375 .277 & 24,5 & 27,6 & 14193 & 18,5 & 27,4 \\
\hline
\end{tabular}

Fonte: Censo Demográfico 2010, microdados da amostra. 
TABELA 2

Distribuição padronizada das uniões por raça/cor dos casais, segundo condição marital, situação do domicílio e tipo do município

Brasil - 2010

Em porcentagem

\begin{tabular}{lcccccc}
\hline \multirow{2}{*}{ Raça/cor do homem } & \multicolumn{7}{c}{ Raça/cor da mulher - casadas } \\
\cline { 2 - 7 } & Branca & Preta & Amarela & Parda & Indígena & Total \\
\hline Branco & 64,1 & 11,0 & 3,9 & 18,3 & 2,6 & 100,0 \\
Preto & 9,3 & 71,0 & 4,3 & 13,6 & 1,8 & 100,0 \\
Amarelo & 4,6 & 4,5 & 84,8 & 4,8 & 1,3 & 100,0 \\
Pardo & 19,5 & 11,6 & 5,6 & 61,1 & 2,2 & 100,0 \\
Indígena & 2,5 & 1,9 & 1,5 & 2,2 & 92,0 & 100,0 \\
Total & 100,0 & 100,0 & 100,0 & 100,0 & 100,0 & \\
Total valor absoluto & 13.948 .003 & 1.427 .940 & 323.179 & 9.287 .358 & 39.769 & 25.026 .249 \\
\hline
\end{tabular}

\begin{tabular}{|c|c|c|c|c|c|c|}
\hline \multirow{2}{*}{ Raça/cor do homem } & \multicolumn{6}{|c|}{ Raça/cor da mulher - unidas } \\
\hline & Branca & Preta & Amarela & Parda & Indígena & Total \\
\hline Branco & 56,7 & 14,6 & 5,4 & 20,2 & 3,1 & 100,0 \\
\hline Preto & 13,7 & 61,9 & 7,4 & 15,2 & 1,8 & 100,0 \\
\hline Amarelo & 5,5 & 8,4 & 77,0 & 7,3 & 1,8 & 100,0 \\
\hline Pardo & 21,2 & 12,9 & 8,2 & 54,8 & 2,8 & 100,0 \\
\hline Indígena & 2,9 & 2,1 & 1,9 & 2,5 & 90,6 & 100,0 \\
\hline Total & 100,0 & 100,0 & 100,0 & 100,0 & 100,0 & \\
\hline Total valor absoluto & 5.384 .500 & 1.201 .954 & 156.698 & 6.451 .892 & 37.128 & 13.232 .172 \\
\hline \multirow{2}{*}{ Raça/cor do homem } & \multicolumn{6}{|c|}{ Raça/cor da mulher - residente em área urbana } \\
\hline & Branca & Preta & Amarela & Parda & Indígena & Total \\
\hline Branco & 61,0 & 12,5 & 4,3 & 19,0 & 3,3 & 100,0 \\
\hline Preto & 10,9 & 67,0 & 5,0 & 15,0 & 2,1 & 100,0 \\
\hline Amarelo & 5,0 & 5,3 & 82,8 & 5,2 & 1,7 & 100,0 \\
\hline Pardo & 20,1 & 12,8 & 6,0 & 58,1 & 3,0 & 100,0 \\
\hline Indígena & 3,0 & 2,4 & 1,9 & 2,8 & 89,9 & 100,0 \\
\hline Total & 100,0 & 100,0 & 100,0 & 100,0 & 100,0 & \\
\hline Total valor absoluto & 16.912 .067 & 2.229.302 & 416.466 & 12.600 .608 & 62.503 & 32.220 .946 \\
\hline \multirow{2}{*}{ Raça/cor do homem } & \multicolumn{6}{|c|}{ Raça/cor da mulher - residente em área rural } \\
\hline & Branca & Preta & Amarela & Parda & Indígena & Total \\
\hline Branco & 66,8 & 10,4 & 3,5 & 18,2 & 1,1 & 100,0 \\
\hline Preto & 9,2 & 70,7 & 6,7 & 12,4 & 0,8 & 100,0 \\
\hline Amarelo & 3,6 & 7,6 & 81,1 & 7,1 & 0,7 & 100,0 \\
\hline Pardo & 19,2 & 10,4 & 8,0 & 61,3 & 1,1 & 100,0 \\
\hline Indígena & 1,2 & 0,8 & 0,6 & 1,1 & 96,4 & 100,1 \\
\hline Total & 100,0 & 100,0 & 100,0 & 100,0 & 100,0 & \\
\hline Total valor absoluto & 2.420 .437 & 400.592 & 63.411 & 3.138 .641 & 14.393 & 6.037 .474 \\
\hline
\end{tabular}

\begin{tabular}{|c|c|c|c|c|c|c|}
\hline \multirow{2}{*}{ Raça/cor do homem } & \multicolumn{6}{|c|}{ Raça/cor da mulher - residentes em municípios com TI } \\
\hline & Branca & Preta & Amarela & Parda & Indígena & Total \\
\hline Branco & 62,2 & 13,3 & 4,7 & 18,1 & 1,8 & 100,0 \\
\hline Preto & 11,4 & 69,6 & 3,2 & 14,2 & 1,6 & 100,0 \\
\hline Amarelo & 5,5 & 3,0 & 87,4 & 3,5 & 0,6 & 100,0 \\
\hline Pardo & 19,2 & 12,3 & 4,1 & 61,9 & 2,5 & 100,0 \\
\hline Indígena & 1,7 & 1,8 & 0,6 & 2,3 & 93,6 & 100,0 \\
\hline Total & 100,0 & 100,0 & 100,0 & 100,0 & 100,0 & \\
\hline Total valor absoluto & 2.194 .617 & 244.099 & 80.613 & 1.718 .609 & 25.083 & 4.263 .022 \\
\hline \multirow{2}{*}{ Raça/cor do homem } & \multicolumn{6}{|c|}{ Raça/cor da mulher - residentes em municípios sem TI } \\
\hline & Branca & Preta & Amarela & Parda & Indígena & Total \\
\hline Branco & 61,6 & 12,0 & 4,2 & 18,7 & 3,5 & 100,0 \\
\hline Preto & 10,6 & 67,1 & 5,7 & 14,5 & 2,1 & 100,0 \\
\hline Amarelo & 4,7 & 6,2 & 81,2 & 5,9 & 2,0 & 100,0 \\
\hline Pardo & 19,9 & 12,3 & 6,8 & 58,2 & 2,9 & 100,0 \\
\hline Indígena & 3,2 & 2,4 & 2,2 & 2,7 & 89,5 & 100,0 \\
\hline Total & 100,0 & 100,0 & 100,0 & 100,0 & 100,0 & \\
\hline Total valor absoluto & 17.137 .886 & 2.385 .795 & 399.264 & 14.020 .640 & 51.814 & 33.995 .399 \\
\hline
\end{tabular}

Fonte: Censo Demográfico 2010, microdados da amostra. 